\title{
Temporal aspects of poetry readings by authors and adults
}

\author{
LINDA FUNKHOUSER \\ Southern Illinois University, Edwardsville, Illinois 62026 \\ and \\ DANIEL C. O'CONNELL \\ Saint Louis University, Saint Louis, Missouri 63103
}

\begin{abstract}
Recorded readings of three poems were analyzed: "Buffalo Bill's" by E. E. Cummings, "The Death of the Ball Turret Gunner" by Randall Jarrell, and "Dust of Snow" by Robert Frost. Readings were by the respective authors, 10 university professors of English, and 10 adults. A rhetorical or expressive use of both more frequent and longer silent pauses by the authors was predicted relative to professors and adults. This was confirmed, except for the shorter pauses of Frost. Both speech rate and articulation rate of authors were dramatically slower than those of the control groups. Only negligible differences were found between the control groups.
\end{abstract}

It has long been recognized by literary scholars that recordings of poetry readings could be analyzed empirically in terms of their temporal aspects. Frost acknowledged rather quaintly as early as 1914 that "the psychologist can actually measure this with a what-do-you-callit" (Thompson, 1964, pp. 107-108). Richards (1929, pp. 227-228) suggested in his Practical Criticism a similar application of instrumentation "designed to record ... all the physical characters of the sequences of sounds" in verse. More recently, Fussell (1965, p. 21) recommended an instrumental acoustic measure of scansion as having "the advantage of accuracy, especially in its representations of many of the empirical phenomena of verse when it is actually spoken."

An early beginning of such analyses was made by Snell (1918a, 1918b) for a passage of Milton's "Paradise Lost." Her results have recently been confirmed by Dillon (1976, p. 12). He summarizes a model of what he calls "strategies for pause placement": "Readers aim for at least one pause per line, usually line-final, but also line-medial; . . . there are generally recognized constraints on insertion of substantial pauses in sequences of simple-sentence elements, and these constraints generally block realization of expected pauses; . . . some readers rely more on punctuation to guide pause placement than others who select from the commas the ones at which they will pause. The c-pausers prefer to reserve pauses for clause-boundaries if the rhythmic expectation is not urgent."

In another recent empirical investigation, Meinhold (1967) found more frequent use of silent pauses in German poetry readings than in readings of more prosaic genre; mean length of silent pauses varied non- significantly across genre. Kowal, O'Connell, O’Brien, $\&$ Bryant (1975, p. 563), however, found an increase in both frequency and mean length of silent pauses in poetry readings over prose readings, and a corresponding decrease in speech rate and length of phrases uninterrupted by a silent pause-"a pattern of temporal responses that could correctly be called rhetorical or expressive."

But, in general, literary scholars have quite neglected empirical approaches to poetry analysis in favor of more intuitive methods.

The present research is a logical sequel to Kowal et al. (1975). Its rationale is to generalize their findings regarding expressive or rhetorical use of silent pauses to a different set of poems, considerably better known and of varying styles and lengths: "Buffalo Bill's" (BB) by E. E. Cummings (1954, p. 50), "The Death of the Ball Turret Gunner" (TG) by Randall Jarrell (1969, p. 144), and "Dust of Snow (DS) by Robert Frost (1969, p. 221). They are, respectively, 56, 58, and 36 syllables in length.

A logical extension of the rhetorical or expressive hypothesis is introduced. The author of a poem is expected to have a very special appreciation of its rhetorical implications. Hence, his rendition of it should manifest par excellence its expressive potential. Recorded readings by the authors of their respective poems were therefore analyzed. Two additional groups of readers were included for purposes of comparison. Ten university professors of English and 10 adults each read the three poems. Specifically, then, the authors were expected to have relatively more frequent and longer silent pauses and a correspondingly lower speech 
rate and phrase length (between silent pauses) than the college professors, and they, in turn, than the adults.

\section{METHOD}

Readings of the respective authors were taken from published recordings: "Buffalo Bill's Defunct," Library of Congress Tape NCP16-3395; Randall Jarrell reads and discusses his poems against war, Caedmon TC1363; and Robert Frost reading, National Council of Teachers of English B17540. The 10 English professors, seven men and three women, were all from the Department of English, Southern Illinois University, Edwardsville. All held terminal degrees and had at least several years of university teaching experience. The 10 adults had no special training, experience, or interest in poetry. There were five men and five women with educational backgrounds varying from high school to terminal degrees. Both groups contained only normal native Caucasian speakers of Midland American English.

The professors and adults each read all three poems aloud after having read them over and practiced as they wished. Recordings were made unobtrusively, but with the knowledge and consent of the subjects, by means of a Wollensak tape recorder and in the presence of the first author.

Verbatim transcriptions were made of all the recordings. Only among the adults did any errors occur. In readings of BB, three subjects read in two, two, and one supernumerary syllables, respectively, and a fourth subject omitted a syllable. One subject added three syllables to TG, and ne subject added two syllables to DS. All supernumerary syllables were deleted from both the syllabic and temporal data.

Temporal data were produced from the sound recordings in terms of amplitude of acoustic energy over time by means of a Brüel and Kjaer af spectrometer (Type 2112) and level recorder (Type 2305). From these data, the length of readings in milliseconds and the number and length of silent or unfilled pauses (UPs) were determined. The minimum length of UPs was set at $270 \mathrm{msec}$. Speech rate and articulation rate were measured in syllables per second $(\mathrm{syl} / \mathrm{sec})$. Phrase length was defined as the number of syllables between UPs.

\section{RESULTS}

Superficially, the design of the experiment appears to lend itself to a 3 by 3 (poems by groups) analysis; however, it should be remembered that authors' readings were of only their own poetry. Each author's reading can logically be considered an optimal or model performance which the author considers an appropriate vocal presentation of the poem itself.

A 3 by 2 (poems by groups) analysis of variance was performed on all the response measures listed in Table 1. For these measures, differences between the two groups were nonsignificant. Consequently, Table 1 presents for the respective poems a combined control group in comparison with the author. Each poem is presented separately because (1) the 3 by 2 analysis of variance yielded significant differences between them on all response measures and (2) the author's response measures were for his own poetry only. In other words, there are no authors' response measures across poems.

Table 1 suggests some logical comparisons of great interest. The individual comparisons between author and group for each of the three poems on reading time, speech rate, and articulation rate exemplify a rather rare statistical case. In each instance, not one of the 20 measures contributing to the group mean overlaps the author's response measure. In the absence, therefore, of any reason for such differences other than the experimental hypothesis itself, there is no need for inferential statistics. In fact, in only four of the individual comparisons between author and group in Table 1 are there more than a single overlapping measure. In only one of these instances is the difference between author and group either negligible or in the nonpredicted direction. The single instance involves the measure of length of UPs for DS, where the author's mean length was shorter than the group's $(485<522 \mathrm{msec})$.

\section{DISCUSSION}

A modest disclaimer is not out of place at the outset of this discussion. It well may be that the basic methodology of this experiment will prove to be far more important for literary criticism than for psycholinguistics. The actual performance of poets in reading their own poetry has not been subjected to detailed empirical analysis heretofore. The analyses of Funkhouser (1978, in press) have already served as corrective to literary critical positions long taken for granted regarding the poems used in this study. The increasing availability of authors' recordings of their own works offers a

Table 1

Temporal Measures of Authors and Group Means (Professors and Adults Combined) for Readings of Three Poems (BB, TG, and DS)

\begin{tabular}{|c|c|c|c|c|c|c|}
\hline \multirow[b]{3}{*}{ Temporal Measures } & \multicolumn{6}{|c|}{ Poems } \\
\hline & \multicolumn{2}{|c|}{ BB (56 syl) } & \multicolumn{2}{|c|}{ TG (58 syl) } & \multicolumn{2}{|c|}{ DS (36 syl) } \\
\hline & Author & Group & Author & Group & Author & Group \\
\hline Reading time (sec) & 24.63 & 15.77 & 28.17 & 17.54 & 13.60 & 10.63 \\
\hline UP time (sec) & 5.20 & 2.94 & 10.52 & 3.69 & 2.91 & 1.24 \\
\hline Percentage UP time & 21.1 & 17.8 & 37.3 & 20.4 & 21.4 & 12.0 \\
\hline Speech rate (syl/sec) & 2.27 & 3.62 & 2.06 & 3.37 & 2.65 & 3.59 \\
\hline Articulation rate (syl/sec) & 2.88 & 4.39 & 3.28 & 4.23 & 3.37 & 3.96 \\
\hline Number UPs/syl & .107 & .084 & .190 & .098 & .167 & .067 \\
\hline Mean UP length (msec) & 867 & 622 & 955 & 641 & 485 & 522 \\
\hline UP length (msec)/syl & 93 & 53 & 181 & 64 & 81 & 34 \\
\hline Phrase length (syl/UP) & 8.00 & 11.07 & 4.83 & 9.26 & 5.14 & 11.73 \\
\hline
\end{tabular}


fertile field for such an empirically based literary criticism. The rhetorical or expressive hypothesis posited in this study was resoundingly confirmed. The elevated reading time of the authors over both control groups is largely due to increases in both absolute amount and percentage of UP time. The overall speech rate of $2.26 \mathrm{syl} / \mathrm{sec}$ for the authors is extraordinarily slow. In fact, it is almost as slow as that of second-graders' poetry readings in the Kowal et al. (1975) study. But one could hardly argue that the same reasons prevail in the present case. The fact that the authors' and professors' readings were completely errorless clearly indicates that we are not dealing with differential difficulty as a source of this extremely slow speech rate.

The deviation of the authors' readings from the adult norms for the three poems in Kowal et al. (1975, p. 562) is in sharp contrast with the convergence of the professors' and adults' readings with those same norms. Reference to Table 1 confirms the similarity of speech rates for the combined group of professors and adults, those of graduate students in the previous study on the three poems $(3.7,3.7$, and $3.5 \mathrm{syl} / \mathrm{sec}$, respectively), and those of a comparable group of college professors in the previous study $(3.7,3.4$, and $3.2 \mathrm{syl} / \mathrm{sec}$, respectively). The corresponding mean lengths of UPs from the previous study for graduate students $(632,586$, and $595 \mathrm{msec}$, respectively) and professors (641, 669, and $677 \mathrm{msec}$, respectively) are also comparable.

The mean length of UPs for DS is clearly out of line with all the other measures. Paradoxically, the finding is not genuinely counter to the rhetorical or expressive hypothesis of the experiment. As the shortest and most reserved in its affective tone of all these poems, DS might be expected to manifest some variant trends. On all the other response measures, the picture that emerges for DS is the same as for the other poems. In addition, Frost has been noted for "a swaying monotone," "almost a drone": "The impression is . . . that Frost often simply talked through many of his poems" (Funkhouser, 1978, p.192).

The experimental findings are consistent with Dillon (1976) and Meinhold (1967), as well as with Kowal et al. (1975). A finding not expected and not hypothesized to be part of the rhetorical or expressive temporal pattern is the extraordinarily slow articulation rates of the authors. E. E. Cummings, for example, articulated $1.51 \mathrm{syl} / \mathrm{sec}$ less than the control group in BB. Undoubtedly, this retardation of articulation rate contributes to the rhetorical function, in addition to the major contribution of silent pauses.

The present research clearly confirms the hypothesis that an author utilizes the rhetorical or expressive potential of UPs and slower speech rate, sometimes to an extraordinary degree, in the effort to produce an optimal performance of his own work. The authors' use of slower articulation rates for the same purpose was an unexpected finding, though consistent with the general rhetorical or expressive hypothesis.

Perhaps the most surprising result of this experiment was the alignment of the professors with the adults, rather than with the authors, on all temporal measures, without exception. This not only makes the rhetorical effect in the authors more prominent, but raises as well a question of the professors' appreciation or subjective definition of the poetry. Apart from their lower error rate, there is no instance in which the professors' temporal measures of expressiveness resembled those of the authors more than those of the adults. The finding may well reflect the tendency in our culture, even on the part of professors of English, to limit their appreciation or subjective definition of poetry to silent reading of a written text, rather than indulging the leisure and luxury of reading aloud. Put all too simply, the reality of a poem for the individual reader is not the same in silent and aloud reading. Stereotypically, our culture defines poetry more and more by the silent reading mode. The number of literate people in our culture who are addicted to reading poetry at all is probably minuscule; the number addicted to reading poetry aloud is even less. Small wonder, then, if poets appear in a study such as this to be alone in the expressive appreciation of their own poetry to an extent far beyond our expectations.

The experimental results can be brought to bear on yet another aspect of the rhetorical or expressive function of temporal phenomena. Expressiveness is not purely cognitive; it is not the result solely of an intellectual appreciation of the written message. Instead, it involves an affective and emotional facet as well, an enactment of poetic mood: urgency, pathos, joy, disdain, grandeur. The relatively muted expressiveness of the professors and of Frost reflects a rather stereotypic picture of the intellectual: controlled, correct clarity. In other words, they manifest the cognitive component of expressiveness without a salient affective component.

These considerations suggest not only a broad empirical spectrum for the concept of expressiveness, but also experimental groups other than poets themselves who might well manifest a strong experimental effect due to the affective component of expressiveness. These groups would include performing artists, such as actors and singers, for whom vocalization is experienced habitually as artistic instrumentation for affect and emotion. Literateurs whose artistic milieu is outside higher education might manifest similar ability and freedom to indulge affective expressiveness.

The present study represents only the slightest probe into the riches of literary expressiveness and makes no claim of comprehensively treating that concept, even in its empirical manifestations. The method itself is psycholinguistic, but the applications appear to have great promise for an interdisciplinary understanding of literary criticism and literary appreciation.

\section{REFERENCES}

Cummings, E. E. Buffalo Bill's. Poems 1923-1954. New York: Harcourt, Brace, 1954.

Dillon, G. L. Clause, pause, and punctuation in poetry. Linguistics, 1976, 169, 5-20.

Frost, R. Dust of snow. In E. C. Lathem (Ed.), The poetry of Robert Frost. New York: Holt, Rinehart, \& Winston, 1969.

FUN KHOUSER, L. Acoustical rhythm in performances of three 20thcentury American poems. Unpublished doctoral dissertation, Saint Louis University, 1978.

Funkhouser, L. Acoustical rhythms in E. E. Cummings' "Buffalo Bill's." Journal of Modern Literature, in press.

Fussell, P. Poetic meter and poetic form. New York: Random House, 1965.

JARRELL, R. The death of the ball turret gunner. The complete poems. New York: Farrar, Straus, \& Giroux, 1969.

Kowal, S., O'Connell, D. C., O’Brien, E. A., \& Bryant, E. T. Temporal aspects of reading and speaking: Three experiments. American Journal of Psychology, 1975, 88, 549-569.

Meinhold, G. Quantität und Häufigkeit von Pausen in gelesenen deutschen Texten in Zusammenhang mit dem Sprechtempo. Wissenschaftliche Zeitschrift der Friedrich-Schiller-Universität Jena, 1967, 1, 107-111.

Richards, I. A. Practical criticism. New York: Harcourt, Brace, \& World, 1929.

SNELl, A. L. F. An objective study of syllabic quantity in English verse. Publication of the Modern Language Association, 1918, 33, 396-408. (a)

SNELl, A. L. F. Pause: A study of its nature and its rhythmical function in verse, especially blank verse. In F. N. Scott (Ed.), Contributions to rhetorical theory (Vol. 8). Ann Arbor: Ann Arbor Press, 1918. (b)

Thompson, L. (Ed.). Selected letters of Robert Frost. New York: Holt, Rinehart, \& Winston, 1964.

(Received for publication August 7, 1978.) 